imagen muy popular en Madrid esta Virgen del Buen Parto del escultor Salvador Carmona, pero nada, ni siquiera una vieja fotografia, hemos hallado que nos ponga sobre una posible pista de la imagen.

Juan Nicolau Castro

Doctor por la Universidad Autónoma

\title{
CONSIDERACIONES SOBRE PINTURA EN TIERRA DE CAMPOS: NUEVAS ATRIBUCIONES A LOS MAESTROS DE ASTORGA Y DE BECERRIL
}

La pintura castellano-leonesa del siglo XVI comprende un vasto territorio que dificulta el conocimiento total de la misma, necesario para establecer conexiones entre las distintas escuelas; si a este hecho unimos la falta en mucho casos de la documentación proveniente de los libros de fábrica, el paisaje se complica. Hay que agradecer a todos los estudiosos que nos precedieron el haber dado a conocer la mayoría de las obras cuya autoría es aún hoy objeto de discusión. En este artículo no se pretende presentar nuevas teorías, sino que con la ventaja de más puntos de referencia, aunque se carece de la documentación pertinente en las dos obras tratadas, estilísticamente podemos aportar nuevas atribuciones que ayudarán a matizar más el panorama planteado.

En la parroquia de Santa María del Castillo en Torremormojón (Palencia) ${ }^{1}$ se encuentra un retablo cuyo cuerpo está formado por tres tablas (fig. 1), la central con la Virgen con el Niño y un donante, a su derecha San Juan Evangelista y a su izquierda San Nicolás; consta también de un banco con otras cinco tablas: San Pedro, San Miguel matando al demonio, Piedad, San Juan Bautista y la Visión de San Bernardo. Estas pinturas han sido tradicionalmente asignadas al Maestro de Calzada, personalidad estilística del primer renacimiento palentino creada por Post ${ }^{2}$, el primero en establecer esta atribución ${ }^{3}$. Este maestro se caracteriza por su formación hispanoflamenca, probablemente en el taller del Maestro Alejo, a la que se añaden fórmulas aprendidas de Pedro Berruguete sobre todo, pero también de Juan de Flandes. Su actividad se sitúa desde los inicios del siglo Xvı hasta el final de la década de los veinte ${ }^{4}$. Algunos investigadores se han desmarcado de la adscripción del retablo de Torremormojón al Maestro de Calzada, pero no han formulado otra autoría ${ }^{5}$. En la pintura palentina de las primeras décadas del siglo Xvi confluye el influjo de los dos pintores citados más arriba, Berruguete y Flandes; dependiendo del seguidor al que nos refiramos, el influjo de uno o de otro artista se hallará más pronunciado, pero al converger las influencias, en muchos casos es difícil discernir paternidades. Desconocemos en la mayoría de los casos los nombres de los pintores de esta épo-

\footnotetext{
' Existen, además de este retablo, dos tablas con Santa Catalina y Santa Lucía de cuerpo entero que no incluimos en nuestro análisis ya que, aunque se trata de pinturas contemporáneas al retablo, son de diferente autoría.

${ }^{2}$ Post, Raymond Chandler: A History of Spanish Painting, vol IX.I, 1947, pp 488-502.

${ }^{3}$ Con anterioridad, había sido atribuido a Juan de Flandes por Navarro García, Rafael: Catálogo Monumental de Palencia, t. IV, 1946 , p. 90 . Sancho Campo sigue parcialmente esta atribución, ya que en el tomo III de El Arte Sacro en Palencia, 1972, lams. 74 y 75 lo vincula al taller de Juan de Flandes.

${ }^{4}$ Silva Maroto, Pilar: «En torno a la pintura del primer tercio del siglo xvi en Palencia: el Maestro de Calzada» Anales de Historia del Arte, nº 6, 1996, pp. 163-189.

${ }^{5}$ Angulo Íñiguez, Diego: Pintura del Renacimiento. Ars Hispaniae, vol. XII, 1954, p. 105, equivoca el nombre de la localidad, al llamarla «Mormojón», le parece uno de los maestros más interesantes del momento; Silva Maroto, Pilar: $O p$ cit. , p. 174; Bermejo, Elisa: Catálogo de Las Edades del Hombre. Memorias y esplendores, Palencia, 1999, pp. 88-90, $\mathrm{n}^{\circ} 19$, considera que la obra del Maestro de Calzada es de inferior calidad.
}

$A E A, \mathrm{LXXV}, 2002,300$, pp. 407 a 446 

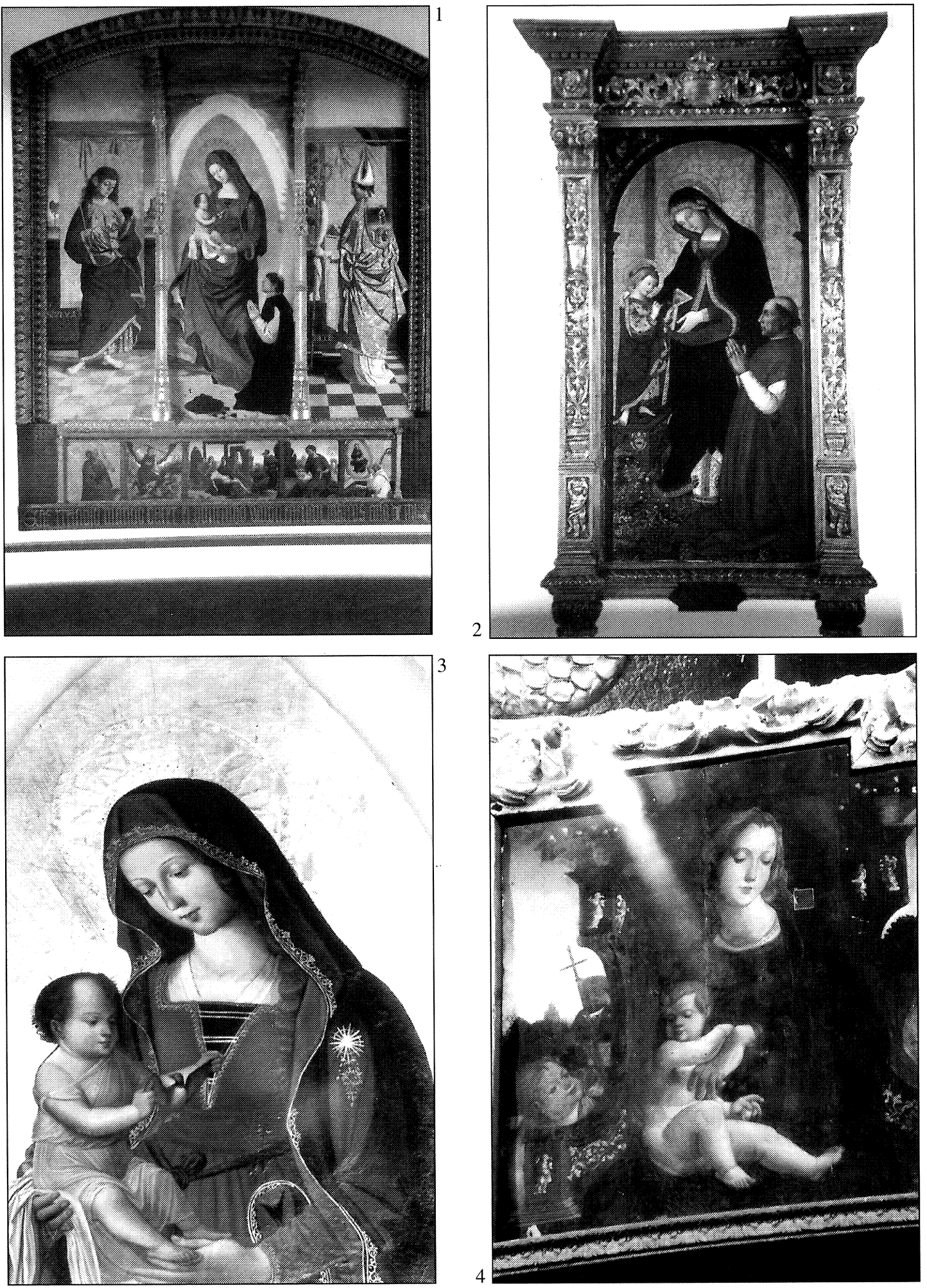

Fig. 1. Maestro de Becerril. Retablo con la Virgen y el Niño con donante. Torremormojón (Palencia)

Fig. 2. Pinturichio. Virgen con el Niño y donante. Museo de Bellas Artes de Valencia.

Fig. 3. Maestro de Becerril. Virgen con el Niño. Torremormojón (Palencia).

Fig. 4. Maestro de Becerril. Virgen entronizada. Retablo de San Pelayo de Becerril de Campos. Catedral de Málaga.

$A E A$, LXXV, 2002, 300, pp. 407 a 446 
ca ${ }^{6}$; dentro de estos numerosos artistas anónimos, una de las personalidades más relevantes es la del Maestro de Becerril, a quien nosotros creemos que pertenece el retablo objeto de este artículo. Desde la formulación del estilo de este pintor, primero por Angulo y luego por Post, se han ido añadiendo varias obras a su catálogo, de diversa calidad pero con indudables conexiones con su estilo, establecido a partir del retablo mayor la iglesia de San Pelayo de Becerril de Campos (Palencia) ${ }^{7}$. Es éste su trabajo más importante conservado cuya adscripción no admite dudas, ya que se trata del retablo princeps, el que vamos a utilizar fundamentalmente para razonar nuestra atribución.

Como se ha dicho, la tabla central del retablo de Torremormojón está ocupada por la Virgen, el Niño y un donante perteneciente al estamento religioso. Fue Post ${ }^{8}$ el primero en resaltar su vinculación con la pintura del mismo tema realizada por Pinturicchio hacia 1495, hoy en Museo de Bellas Artes de Valencia, procedente de Játiva, donde se encontraba desde 1497 al menos (fig. 2). La influencia de Pinturicchio está fuera de toda duda, pero a decir verdad parece que el pintor castellano «modernizó» el modelo. Si bien utiliza duros plegados de influencia flamenca en el manto de la Virgen para conseguir volumen, lo cierto es que las figuras no guardan unas posturas tan rígidas como las de su ejemplo. También el tratamiento del espacio es más avanzado: en la tabla de Pinturicchio, pese al tapizado vegetal del suelo, el espacio se nos aparece como irreal gracias al brocado dorado que cubre todo el fondo; en la pintura de Torremormojón la Virgen está inscrita en una mandorla dorada irradiando luz sobre el resto de la composición, pero no invadiéndola, de modo que el resto del espacio es tangible: parece que el espacio terrenal continúa tras la luz emanada de la Virgen ${ }^{9}$. Dejando aparte este influencia, y centrándonos en la atribución al Maestro de Becerril, el rostro de la Virgen en Torremormojón (fig. 3) es igual al utilizado por este pintor en el retablo de Becerril para la Madonna entronizada (fig. 4); el de San Nicolás (fig. 5) coincide con el del Obispo de Tuy del retablo de San Pelayo, tal y como se aprecia en la escena que representa al Obispo de Tuy en prisión (fig. 6). La figura de San Juan Evangelista (fig. 7) obedece al modelo de uno de esos jóvenes característicos del Maestro de Becerril con un semblante poco dulce, de rasgos que parecen cincelados más que pintados, especialmente los ojos, hundidos como los de los profetas de la colección Adanero ó el San Juan que acompaña a la Virgen en el Santo Entierro del Museo Diocesano de Palencia (fig. 8). Respecto al banco, el rostro de San Miguel (fig. 9) guarda gran parecido con el de las santas del banco de Becerril (fig. 10) o los verdugos del Martirio de San Pelayo; la Piedad se puede poner en relación con otras similares, como la del retablo en Santa María de Astudillo o la que se hallaba en el Hospital de San Antolín de Palencia ${ }^{10}$.

A propósito de esta influencia de Juan de Flandes, la pintura del Maestro de Becerril debe mucho a este pintor, sobre todo en los paisajes, pero, como se apuntaba más arriba, también es fundamental el influjo de Berruguete. El Maestro de Becerril adopta una brillante solución de compromiso entre ambas influencias en la tablas de San Juan y San Nicolás: no renuncia a los fondos dorados tan queridos por Berruguete, pero al mismo tiempo no se conforma con esta opción, sino que tras el brocado se adivina el paisaje muy inspirado en Juan de Flandes. Hay otros muchos ejemplos en éste y otros pintores del momento de la combinación de fondo dora-

\footnotetext{
${ }^{6}$ Para un mayor conocimiento de los pintores activos en el primer tercio, v. Silva Maroto, P.: «Notas sobre la pintura del primer tercio del xvi en Palencia» Actas del VIII Congreso Nacional de Historia del Arte. Cáceres, 3-6 de Octubre de 1990,Cáceres, 1991, pp.323-330, donde se recoge la bibliografía anterior sobre el tema.

7 Dispuesto actualmente en un ensamblaje rococó en una capilla de la catedral de Málaga.

${ }^{8}$ Post, Op. cit. 1947, p. 496.

${ }^{9}$ Además de esta «modernización» hay que reseñar la notable diferencia entre los Niños de ambas pinturas. Siempre cabe la posibilidad de que no fuera esta obra en concreto, de las muchas variaciones sobre el mismo tema que hizo Pinturicchio de la Madonna, en la que se basó el Maestro de Becerril.

${ }^{10}$ Reproducida por Post, Op. cit., fig. 163.

AEA, LXXV, 2002, 300, pp. 407 a 446
} 

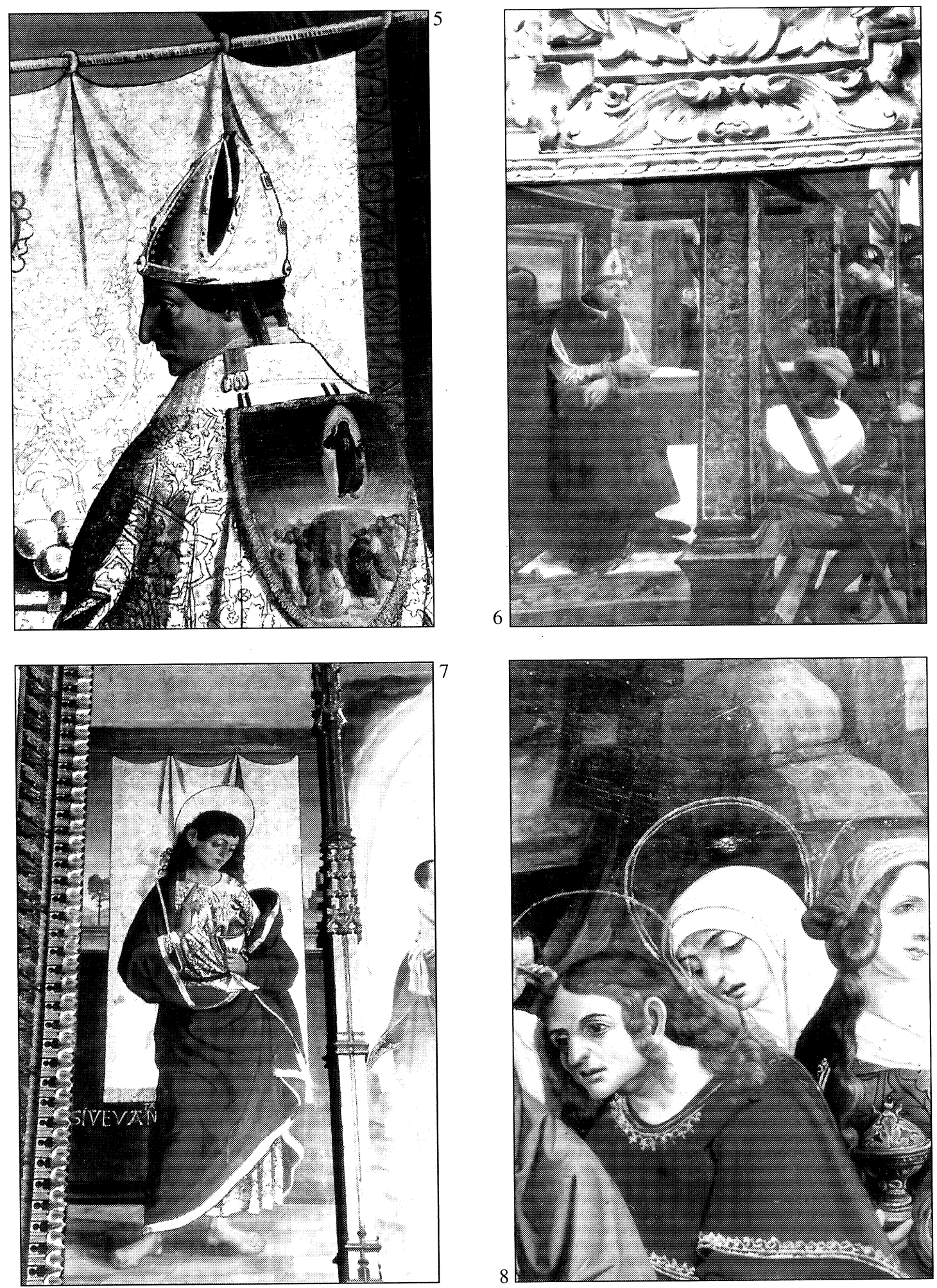

Fig. 5. Maestro de Becerril. San Nicolás. Torremormojón (Palencia).

Fig 6. Maestro de Becerril. El Obispo de Tuy en prisión. Retablo de San Pelayo de Becerril de Campos. Catedral de Málaga.

Fig. 7. Maestro de Becerril. San Juan Evangelista. Torremormojón (Palencia).

Fig. 8. Maestro de Becerril. Santo Entierro (detalle). Museo Diocesano de Palencia.

AEA, LXXV, 2002, 300, pp. 407 a 446 
do y paisaje ${ }^{11}$. Lo que nos parece ingenioso en el caso del Maestro de Becerril es que no se conforma con superponer ambos, sino que al adoptar el fondo dorado la función de cortina, colgada mediante argollas ${ }^{12} \mathrm{y}$ frunciéndose como una tela cualquiera, hace que este elemento pierda gran parte de su carácter irreal para convertirse en otro objeto material, meramente decorativo, de la realidad concreta.

La zona inferior del retablo está recorrida por una inscripción que dice «Este retablo mandó hacer el honrado varón Esteban Marcos año de MDXI» La última parte de la cifra está confusa y se aprecia un corte para ajustarla al marco (fig. 11). Es éste uno de los varios indicios que nos hablan de un montaje forzado hecho para acoger estas tablas que provendrían de otro retablo. Otro detalle muy significativo es el impropio remate superior de color azul en las tablas que conforman el cuerpo del retablo. La decoración es renacentista, con palmetas que recorren el marco y columnillas que separan las tablas del banco; en cambio, las que separan las pinturas del cuerpo del retablo son finas columnas de decoración gótica que no abarcan la altura total de las tablas. Nuestra hipótesis es que estas columnas están reaprovechadas del primitivo retablo y que el anómalo acabado superior de las tablas se debe a que esta zona iría cubierta en el ensamblaje original. El lapso de tiempo entre uno y otro ensamblaje debió de ser escaso, pues la arquitectura que hoy podemos contemplar es coetánea de las pinturas, y podría haber sido perfectamente la original si no se observaran esos pequeños fallos de ajuste que nos hacen concluir que hubo una estructura anterior. Es bien sabido la coexistencia a principios de siglo de los lenguajes clásico y gótico, por lo que la fecha que ostenta el retablo, 1511, es apropiada para ambos lenguajes. Sin embargo, el corte de la inscripción al final del retablo y el estilo de las pinturas y de otras obras del Maestro de Becerril, fechadas en la tercera década del siglo XVI nos hace pensar en que hubo una cifra más larga. A MDXI se le podría añadir una X más con lo que resultaría 1519, más apropiada para el estilo de las pinturas y donde aún era frecuente el empleo del lenguaje gótico en la arquitectura de los retablos. Es cierto que en este ensamblaje no hay espacio para una X más, pero es cuestión de pocos centímetros; recordemos que no es el ensamblaje original y que la tabla está cortada abruptamente.

Queremos llamar la atención sobre el retablo mayor de la iglesia parroquial de San Pedro de Berrueces, no sólo para dejar constancia de su vergonzoso estado de abandono, que pone en serio peligro su existencia, sino porque ha sido escasamente estudiado pese a su gran calidad. En el catálogo monumental del partido judicial de Medina de Rioseco, García Chico lo relacionó con el foco leonés ${ }^{13}$, lo cual no es de extrañar dado que esta localidad dependía en el siglo XVI de la diócesis de León. Años más tarde, Caamaño ${ }^{14}$ matizó esta influencia al conectarlo con el círculo del Maestro de Astorga, pero rechazando la autoría en concreto de este artista anónimo. Lo vincula con el pintor de la tabla que representa a San Juan en prisión, que fue atribuida por Post al Maestro de Astorga, pero que no ha sido incluida con posterioridad en el corpus de este pintor por ninguno de los estudiosos que se han interesado por la obra del Maestro de Astorga, dada sus diferencias estilísticas con las pinturas de este artista. Nosotros la hemos catalogado recientemente entre las obras del Maestro de los Santos Juanes ${ }^{15}$. La obra de este último se encuentra localizada en lugares pertenecientes en el siglo XVI al obispado leonés y su estilo está

\footnotetext{
1 Sobre este asunto v. Ávila Padrón, Ana: «Oro y tejidos en los fondos pictóricos del Renacimiento español» Anuario del Departamento de Historia y Teoría del Arte, I, 1989, pp. 103-116.

12 Ávila, Op. cit, p.111-112, ya advierte la atención que ponían algunos pintores en vincular los tejidos a la arquitectura a través de cordones o argollas, como en el caso de Berruguete y Borgoña.

${ }^{13}$ García Chico, Esteban: Catálogo monumental de Valladolid. Partido judicial de Medina de Ríoseco. Valladolid, 1959, p. 16.

${ }^{14}$ Caamaño Martínez, Jesús M. ${ }^{\mathrm{a}}$ : «Sobre la influencia de Juan de Borgoña» Boletín del Seminario de Arte y Arqueología, $t$. XXX, 1964, pp. 302-305

${ }^{15}$ Fiz Fuertes, Irune: «A propósito del Maestro de los Santos Juanes», A.E.A., LXXIV, 2001, 295, pp. $258-272$.
}

$A E A, \mathrm{LXXV}, 2002,300$, pp. 407 a 446 
muy vinculado al del Maestro de Astorga. El primero podría haber sido discípulo del segundo; no se trata del mismo maestro en diferentes etapas de su obra, de hecho trabajaron juntos en el retablo de San Facundo y San Primitivo en Cisneros (Palencia), donde se aprecia la mayor calidad del de Astorga. En el retablo de Cisneros se pueden apreciar los puntos en común que tienen ambos maestros, como el peso de la herencia de Juan de Flandes, sobre todo por la importancia concedida a desarrollar una espacialidad con matices lumínicos, la cual también debe mucho al influjo de la escuela umbra, manifiesta además en el tratamiento del paisaje. Pero el Maestro de Astorga permanece fiel a estos principios mientras que el Maestro de los Santos Juanes, más joven, incorpora decididamente a sus obras posteriores las corrientes quinientistas que dominan la pintura española del siglo XVI a partir de los años treinta. Además sus personajes son de trazado más duro, no sólo en sus angulosas facciones, sino en el tratamiento de los ropajes. Los rostros femeninos no consiguen la dulzura de los del Maestro de Astorga, están más cerca del influjo flamenco y alemán que del italiano.

$\mathrm{Si}$ nos atenemos a las obras de segura inclusión en el catálogo del Maestro de Astorga, tales como el retablo de la Pasión en la Catedral de Astorga o las dos ta-
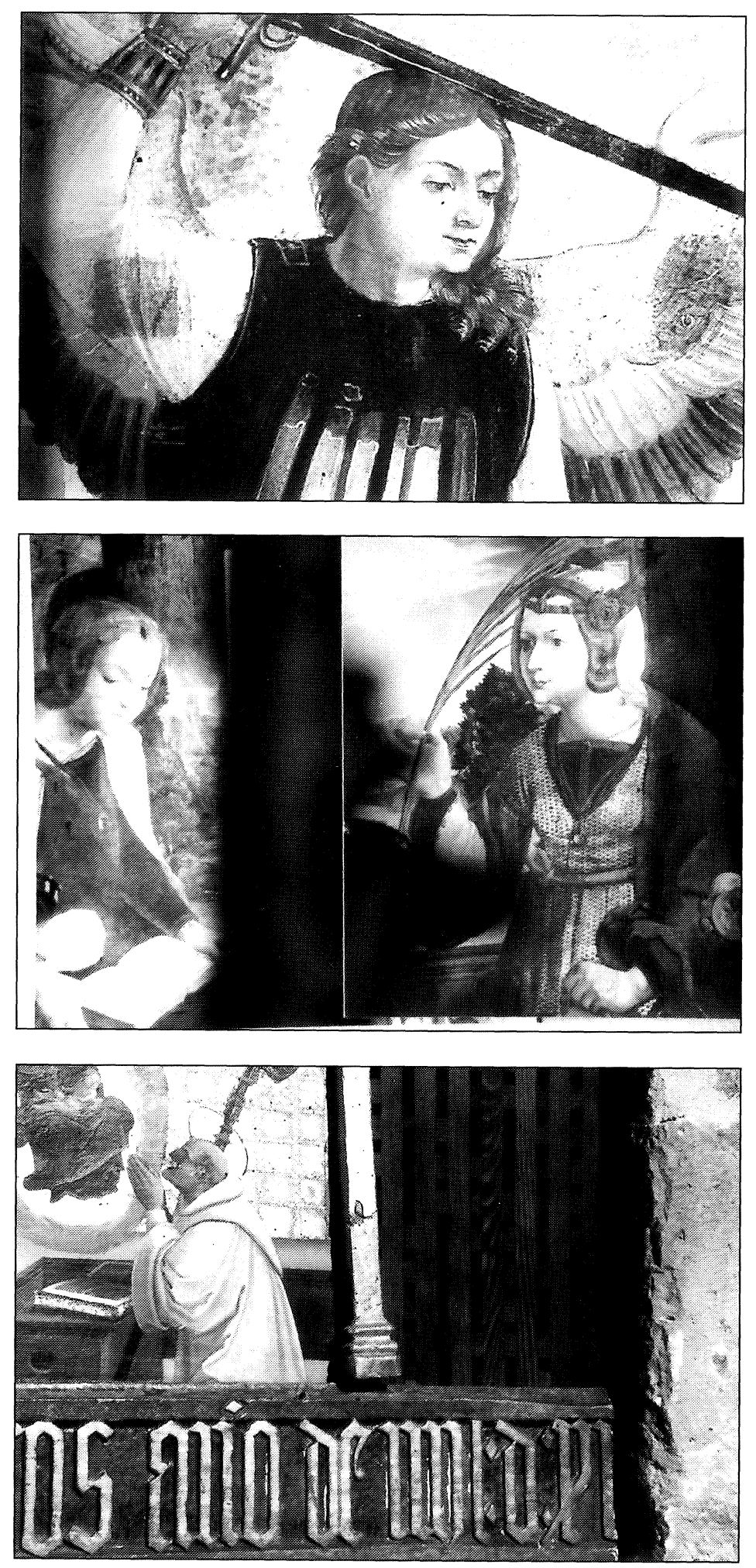

Fig. 9. Maestro de Becerril. San Miguel. Torremormojón (Palencia).

Fig. 10. Maestro de Becerril. Santa Águeda y Santa Catalina. Retablo de San Pelayo de Becerril de Campos. Catedral de Málaga.

Fig. 11. Maestro de Becerril. Remate de la inscripción. Torremormojón (Palencia).

$A E A, \mathrm{LXXV}, 2002,300$, pp. 407 a 446 

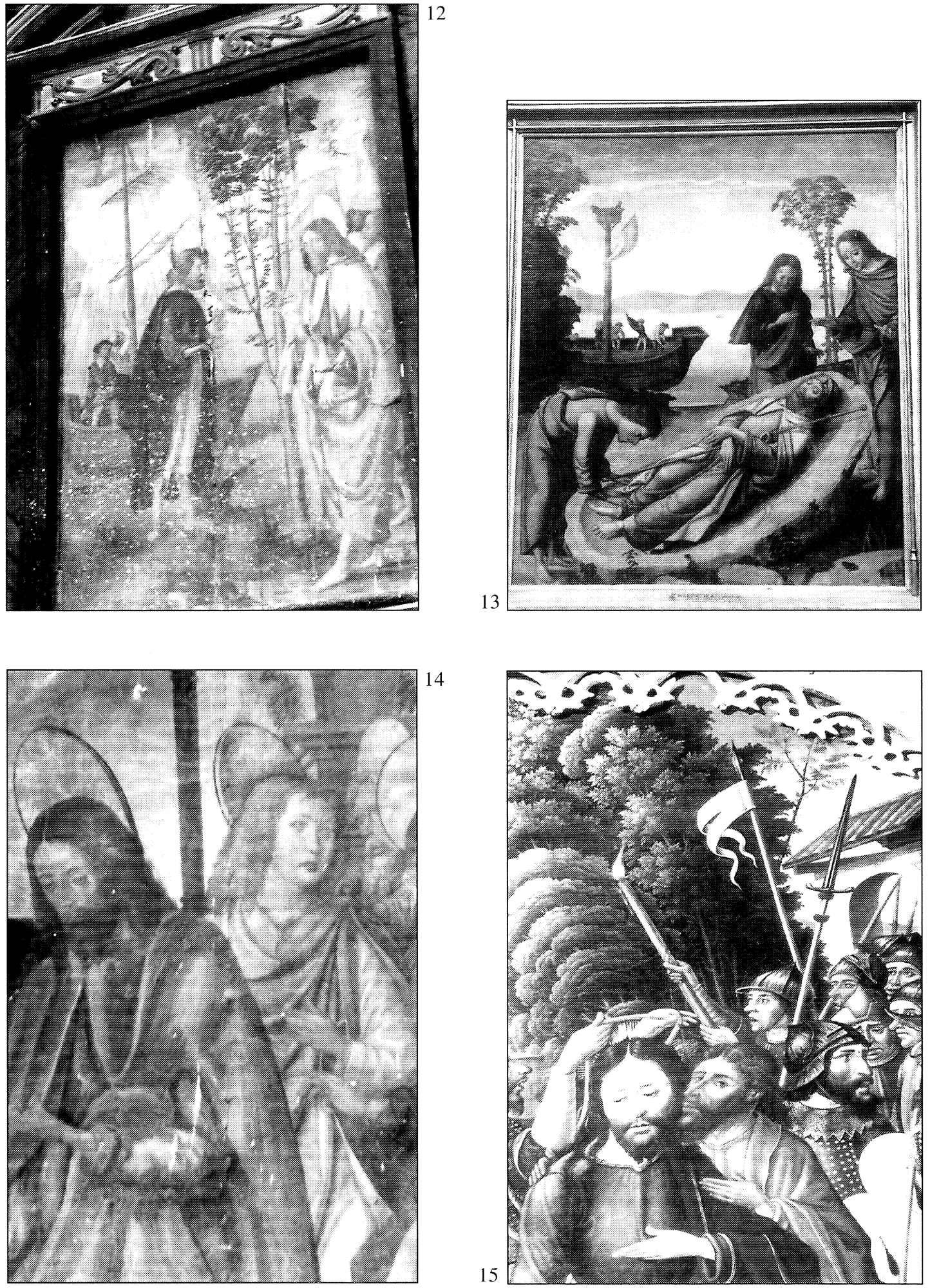

Fig. 12. Maestro de Astorga. Vocación de San Pedro. Berrueces (Valladolid).

Fig. 13. Maestro de Astorga. Llegada del cuerpo del apóstol Santiago a Galicia. Museo Lázaro Galdiano. Fig. 14. Maestro de Astorga. Entrega de las llaves a San Pedro (detalle). Berrueces (Valladolid).

Fig. 15. Maestro de Astorga. Prendimiento de Cristo (detalle). Catedral de Astorga.

AEA, LXXV, 2002, 300, pp. 407 a 446 
blas procedentes de la capilla del cementerio de esta misma ciudad, hoy en el Museo Lázaro Galdiano de Madrid, llegamos a la conclusión de que su autor es el mismo que el de las ocho tablas de Berrueces. Podemos comparar la escena de la Vocación de San Pedro (fig. 12) con la de la Llegada del cuerpo del apóstol Santiago a Galicia (fig. 13), del Museo Lázaro Galdiano, para cerciorarnos de la coincidencia en el tratamiento del espacio y de la atmósfera en estos dos paisajes análogos. Respecto a los tipos humanos, Jesucristo en cualquiera de las escenas en las que aparece en Berrueces, como la Entrega de las llaves a San Pedro (fig. 14) o el Prendimiento de Cristo, coincide con el mismo personaje en el Prendimiento de Cristo (fig. 15) en la catedral de Astorga. San Juan Evangelista, siempre caracterizado casi como un adolescente, en la escena de la Entrega de las llaves (fig. 14) tiene un rostro femenino muy similar al de la Magdalena de la tabla central con el Calvario (fig.16) del retablo de la catedral de Astorga. El titular del retablo de Berrueces, San Pedro, en la escena de su llamada por parte de Cristo, guarda gran parecido con José de Arimatea del citado Calvario en la catedral de Astorga, etc... . Los tocados de los asistentes a la Caída de Simón el Mago (fig. 17), son del mismo tipo que los utilizados por los espectadores de Jesús ante Pilatos (fig. 18) de Astorga. Son tocados pertenecientes a la moda de finales del siglo $\mathrm{XV}$ y principios del siglo XVI ${ }^{16}$.

Examinando las ocho tablas del retablo de Berrueces, Entrega de las llaves a San Pedro, San Pedro corta la oreja a Malco, Vocación de San Pedro, Caída de Simón el Mago en el primer cuerpo, y en el segundo Lavatorio, Quo vadis?, Prendimiento de San Pedro y San Pablo ${ }^{17}$ y Crucifixión de San Pedro ${ }^{18}$, coincidimos con Caamaño en la apreciación de su sabor italianizante ${ }^{19}$. Este estudioso habla de ecos de Mantegna e incluso de Piero della Francesca. El influjo de Mantegna es evidente si comparamos su Tránsito de la Virgen del Museo del Prado con este retablo; el nimbo de los apóstoles es muy parecido: en vez de decantarse, como

${ }^{16}$ Véase a este respecto Bernis, Carmen: «El tocado masculino durante el último cuarto del siglo Xv: los bonetes». A.E.A., XXI, 1948, pp. 20-42; «El tocado masculino durante el último cuarto del siglo Xv: las tocas» A.E.A., XXII, 1949, pp. 111135; comparando los numerosos ejemplos que maneja la autora con el retablo de Berrueces se llega a la conclusión de que el maestro de Astorga utilizó tocados anteriores a los que se llevaban en su época; en el caso de su empleo en el retablo de Astorga se copia casi literalmente el grabado de Durero sobre el mismo tema. En cuanto a los personajes de la Caída de Simón el Mago, no hemos rastreado el uso de ningún grabado, aunque no es una posibilidad que se deba descartar totalmente. La pregunta que surge es la siguiente: ¿Por qué motivo no utiliza la moda de la época?. Pese a el uso casi sin cambios que suele hacer de las estampas durerianas, creemos que un pintor tan dotado como éste no dejaría al azar un detalle tan importante como la indumentaria, al que no solemos dar la debida importancia cuando nos enfrentamos al estudio de una obra plástica. En «La indumentaria de los antepasados de Cristo» (A.A.V.V.: La Capilla Sixtina. Una restauración histórica, pp. 194-223, Barcelona, 1997), Edward Maeder afirma que los personajes que ocupan los lunetos de la Capilla Sixtina visten unos ropajes pasados de moda en la época en que fueron realizados los frescos; muchos de los tocados o ciertas indumentarias tan sólo eran ya utilizadas por judíos; el autor entiende que Miguel Angel quiso dejar claro además de su condición hebrea, la pertenencia de estos personajes al pasado. Esta intencionalidad podría no ser exclusiva de Buonarotti, sino algo extendido en otros artistas. En el caso que nos ocupa, pensamos que el Maestro de Astorga se sirve de bonetes y tocas masculinas pasadas de moda para caracterizar a los hebreos, que, no hay que olvidarlo, fueron expulsados de España en 1492; los que quedaron, convertidos al cristianismo, ya no ostentaban rasgos distintivos en sus ropajes en la época en que fue realizado este retablo.

${ }^{17}$ Caamaño, Op. cit., p. 303, interpreta esta escena como la curación del tullido ante la Puerta Preciosa, pero los dos apóstoles van maniatados, y si en el rostro de uno reconocemos a San Pedro por su identificación con el resto de las tablas, el que le acompaña presenta los rasgos con los que se caracteriza San Pablo, se adivina una larga barba y una incipiente calvicie. Réau no codifica ninguna escena de prendimiento conjunto de ambos santos; la escena que más se asemeja y la que probablemente quiso reflejar el pintor es la de la Despedida de San Pedro y San Pablo ante sus verdugos. RÉAU, Lous: Iconografía del arte cristiano, t. II, vol. 5 Barcelona, 1998, p.65.

${ }^{18}$ El ensamblaje del retablo es más tardío, de finales del siglo xvi, según indica el documento encontrado por García Chico, Op. cit., p.19. Esta circunstancia explica que las tablas no guarden un orden cronológico, pues el retablo original sería desmontado y al volver a ensamblar las tablas en la nueva arquitectura no se conservó la disposición original; también se observan intervenciones posteriores en los las tablas, hay repintes sobre todo en el Lavatorio, en el rostro de Cristo, en el soldado con lanza a la derecha de la Crucifixión de San Pedro y el que se encuentra a la derecha de Cristo en la escena en la que San Pedro corta la oreja a Malco.

${ }^{19}$ Caamaño, Op. cit., p. 304.

AEA, LXXV, 2002, 300, pp. 407 a 446 

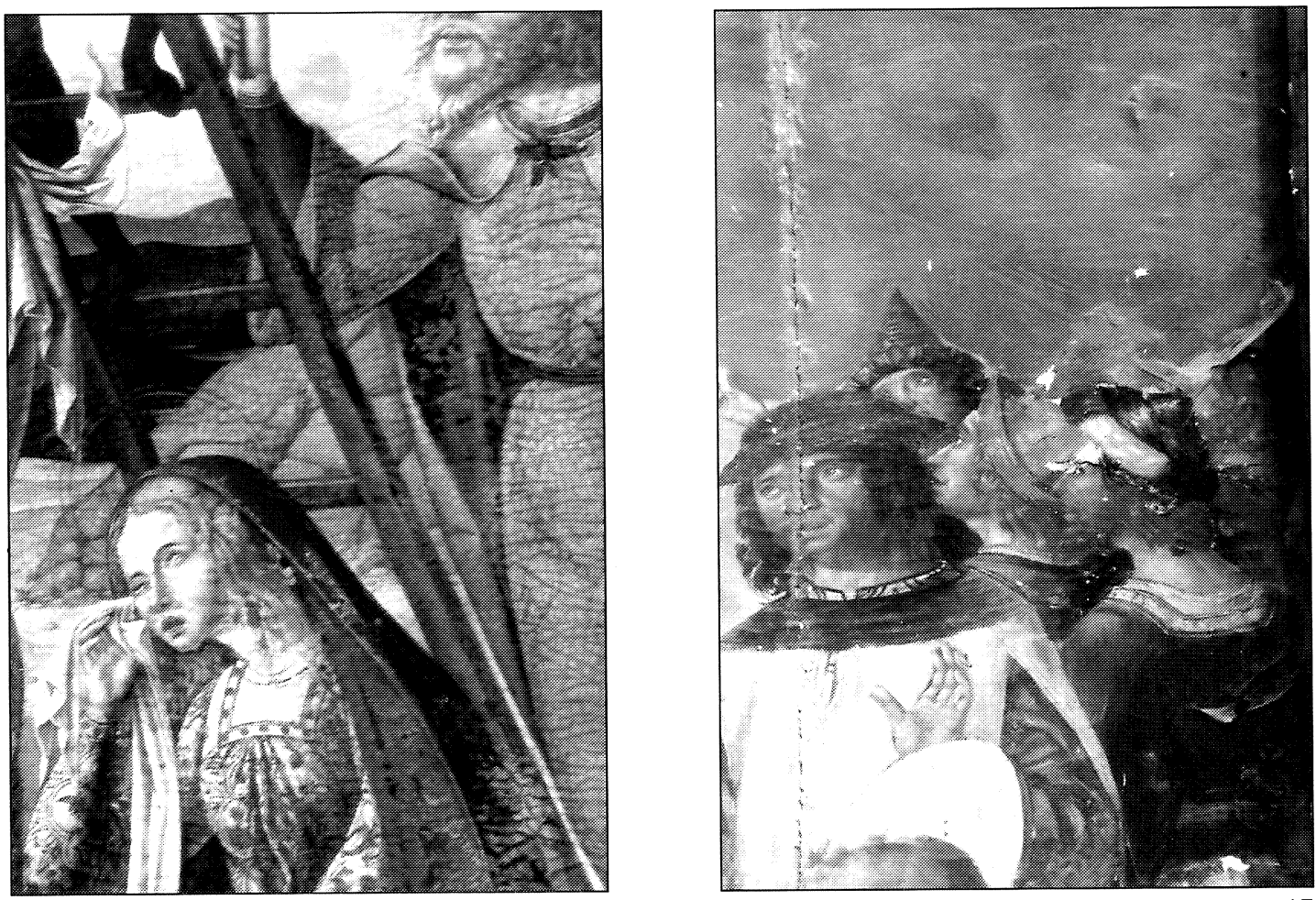

16

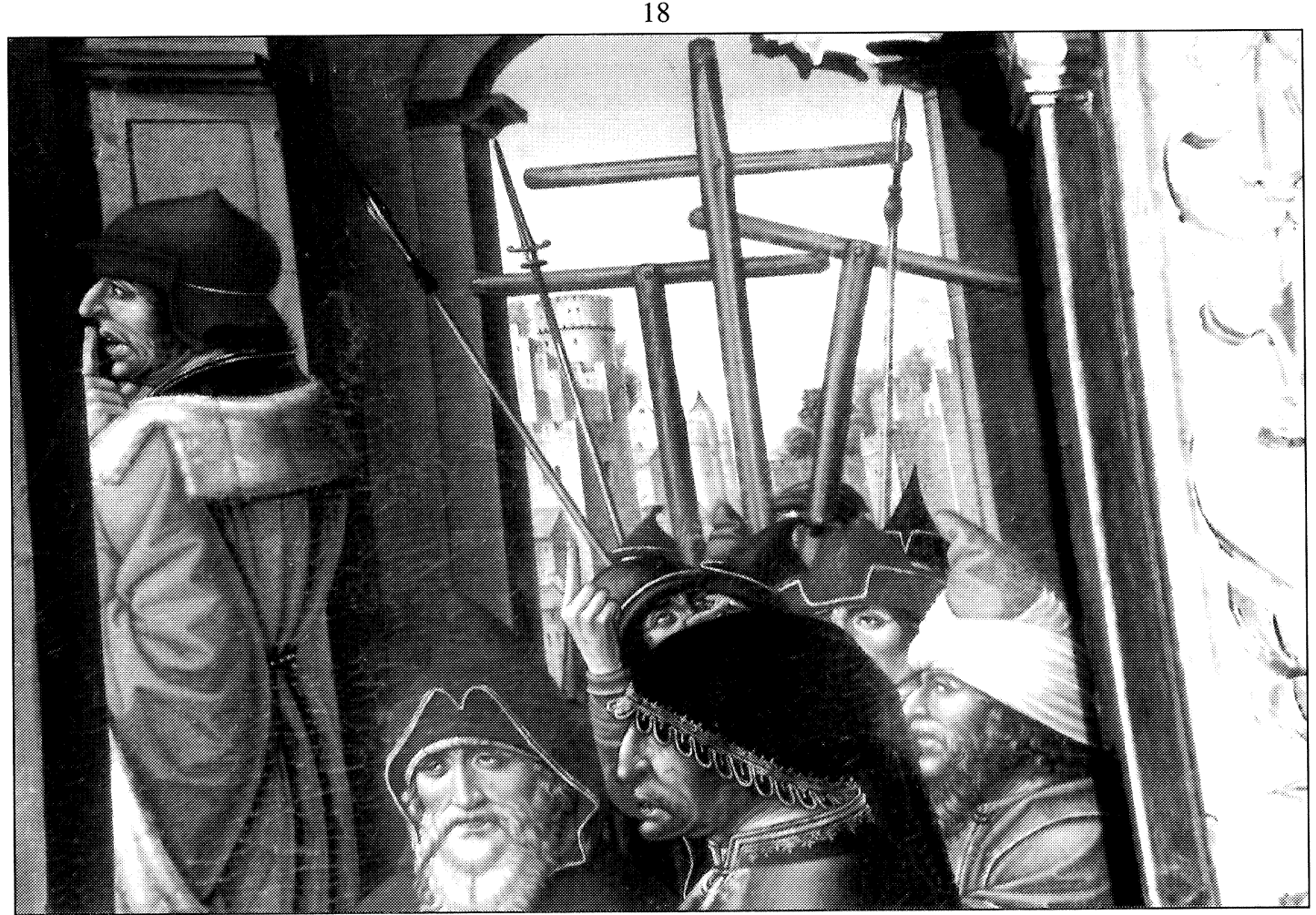

Fig. 16. Maestro de Astorga. María Magdalena (detalle del Calvario). Catedral de Astorga

Fig. 17. Maestro de Astorga. Caída de Simón el Mago (detalle). Berrueces (Valladolid).

Fig. 18. Maestro de Astorga. Jesús ante Pilatos (detalle). Catedral de Astorga.

AEA, LXXV, 2002, 300, pp. 407 a 446 
suele ser habitual, por la representación de un anillo o diadema, ambos artistas optan por colocar encima de la coronilla una especie de disco; otra coincidencia con esta obra de Mantegna es el modo en que las columnas que conforman la arquitectura de las escenas se abren escalonadamente al paisaje del fondo. Sin embargo, nos parece que en las tablas de Berrueces la influencia italiana es eminentemente umbra, en loś paisajes y en la gran preocupación espacial, como ya se ha dicho, pero también en la blanda dulzura de los tipos humanos. El Quattrocento umbro se simplifica con frecuencia centrándolo únicamente en la figura de Perugino. Pero hay artistas como Pinturicchio, formado en el taller del primero, que tiene una personalidad propia. Es más colorista, más decorativo, hace un mayor uso del oro que el resto de sus contemporáneos y sus figuras imitan las de Perugino, pero dotándolas de una mayor languidez. Todas estos rasgos encajan muy bien con el gusto español, por lo que no es extraño que hallemos una fuerte influencia de su obra dentro de nuestras fronteras. En este retablo es evidente en el tratamiento espacial, en la dulzura de sus rostros, y hasta en una de los detalles más peculiares del Maestro de Astorga, su gusto por colocar los rostros de modo oblicuo o simplemente con la cabeza ladeada. Esta característica no es sino la traducción de la expresión de los rostros de las pinturas de Pinturicchio - también de Perugino- que quieren evocar sorpresa o esa gracia lánguida a la que nos referíamos antes. El efecto de esta traslación de gestos en la obra del Maestro de Astorga resulta a veces un tanto caricaturesco por la inferioridad de talento frente a sus modelos italianos, pero en cambio nos permite apoyar su autoría en muchas ocasiones.

Respecto a su datación, teniendo en cuenta que el retablo princeps tiene inscrita la fecha de 1530 en la parte baja del banco ${ }^{20}$, nos inclinamos por considerar muy ligeramente posteriores las tablas de Berrueces por su madurez en el tratamiento espacial y su mayor italianismo observado en la suavidad de los colores, en las arquitecturas renacientes y en las figuras, pese al arcaismo que representan los nimbos dorados. De todos modos, son unas pinturas muy ancladas en el Quattrocento para lo avanzado de la fecha, pero esto es algo habitual en la pintura de Tierra de Campos hasta la llegada del lenguaje manierista de la mano de Alonso Berruguete.

IRUNE Fiz FuerTes

Universidad de Valladolid

\section{CLAUDIO COELLO DECORADOR MURAL: A PROPÓSITO DE UN PROYECTO SUYO PARA LA DECORACIÓN DE UN MURO DE CAPILLA}

Aspecto todavía poco conocido de la producción artística de Claudio Coello (1642-1693) es, sin duda, su labor como decorador mural ${ }^{~}$. Aunque no es mucho lo que se conserva de sus

${ }^{20}$ Gómez Moreno, Manuel: Catálogo monumental de la provincia de León. Madrid, 1925, p. 331.

\footnotetext{
${ }^{1}$ Los estudios monográficos que se han dedicado a esta especialidad de Coello son escasos, limitándose tan sólo a varios artículos importantes y a algunas referencias en sus monografías como artista, entre ellos: E. Tormo, «Actualidad lamentable. Frescos de Coello, Cabezalero y otros, derribados en San Plácido», La Esfera, 6 de marzo de 1908; M. Chamoso Lamas, «Las pinturas de las bóvedas en la Mantería de Zaragoza, obra de Claudio Coello y de Sebastián Muñoz», Archivo Español de Arte (A.E.A.), 1944, pp. 370-382; J.A. Gaya Nuño, Claudio Coello, Madrid 1957, pp.10-13, 18-20; E. J. Sullivan, «Two paintings by Claudio Coello in Valdemoro and his work for the Jesuits in Madrid», Studia Graculatoria, Madrid 1979, 259-266; Id., Claudio Coello y la pintura barroca madrileña, Ed. Española 1989, pp.73-76, 82-84, 101-102, 188-190, 203-205, 241-242.
}

AEA, LXXV, 2002, 300, pp. 407 a 446 